\title{
Pregnancy and Infection
}

\author{
Athena P. Kourtis, M.D., Ph.D., Jennifer S. Read, M.D., M.P.H., and Denise J. Jamieson, \\ M.D., M.P.H. \\ Division of Reproductive Health, National Center for Chronic Disease Prevention and Health \\ Promotion, Centers for Disease Control and Prevention, Atlanta (A.P.K., D.J.J.); and the \\ Department of Epidemiology and Biostatistics, University of California at San Francisco, San \\ Francisco (J.S.R.)
}

Before the advent of antibiotic agents, pregnancy was a recognized risk factor for severe complications of pneumococcal pneumonia, including death. ${ }^{1}$ The influenza pandemic of 2009 provided a more recent reminder that certain infections may disproportionately affect pregnant women. Are pregnant women at increased risk for acquiring infections? Are pregnant women with infection at increased risk for severe disease? During pregnancy, several mechanical and pathophysiological changes occur (e.g., a decrease in respiratory volumes and urinary stasis due to an enlarging uterus), and immune adaptations are required to accommodate the fetus. In this article, we review and synthesize new knowledge about the severity of and susceptibility to infections in pregnant women. We focus on the infections for which there is evidence of increased severity or susceptibility during pregnancy that is not fully explained by mechanical or anatomical changes, and we discuss these infections in light of new findings on immunologic changes during pregnancy.

\section{PREGNANCY AND SEVERITY OF INFECTION}

As compared with nonpregnant women, pregnant women are more severely affected by infections with some organisms, including influenza virus, hepatitis E virus (HEV), herpes simplex virus (HSV), and malaria parasites. The evidence is more limited for organisms that cause coccidioidomycosis, measles, smallpox, and varicella (Table 1). The threshold for diagnostic evaluation, as well as hospitalization and treatment, may be lower for pregnant women than for other patients, and this factor may bias some of the reports of increased disease severity.

\section{INFLUENZA}

Pregnant women are at increased risk for severe illness from influenza virus infection. Cardiopulmonary adaptive changes occurring during pregnancy, such as increased heart rate and stroke volume and reduced pulmonary residual capacity, may increase the risk of

Copyright @ 2014 Massachusetts Medical Society.

Address reprint requests to Dr. Kourtis at 4770 Buford Hwy. NE, MS F74, Atlanta, GA 30341.

No potential conflict of interest relevant to this article was reported.

Disclosure forms provided by the authors are available with the full text of this article at NEJM.org.

The views expressed in this article are those of the authors and do not necessarily represent the official views of the Centers for Disease Control and Prevention. 
hypoxemia and contribute to the increased severity. During the pandemic of 1918, maternal mortality was $27 \%$ (50\% when influenza was complicated by pneumonia), and during the pandemic of $1957,50 \%$ of deaths among reproductive-age women occurred among those who were pregnant. ${ }^{2}$ During the 2009 H1N1 influenza A pandemic, pregnant women were generally at increased risk for severe disease, including disease leading to hospitalization, admission to an intensive care unit, or death, as compared with nonpregnant women and the general population. ${ }^{3}$ In the United States, $5 \%$ of all deaths from pandemic influenza were among pregnant women, although pregnant women represent only about $1 \%$ of the U.S. population. ${ }^{4}$ Higher rates of hospital admission and medical encounters for pregnant women with confirmed or suspected influenza, as compared with the general population, and a greater severity of disease during late pregnancy were also found in interpandemic periods. ${ }^{5-7}$ During the 2009 H1N1 pandemic, as well as during interpandemic periods, women in the third trimester of pregnancy were at increased risk for severe disease (e.g., disease requiring admission to an intensive care unit or resulting in death), as compared with women in an earlier stage of pregnancy. ${ }^{4,6,8}$

\section{HEV INFECTION}

Infection with HEV is also more severe in pregnant women, with high mortality during the third trimester. In areas in which HEV infection is highly endemic (India, Southeast Asia, the Middle East, and Africa), it can be a major cause of maternal death and fetal loss. The pathophysiological basis of this increased mortality is not well understood.

In a review of all consecutive cases of acute liver failure from 1989 to 1996 in a region of India in which HEV infection is endemic, 49 of 83 women of childbearing age with acute liver failure were pregnant (33 in their third trimester). In 47 of these pregnant women, the liver failure was due to HEV infection. ${ }^{9}$ In a case series from India, 33 to $43 \%$ of pregnant women with HEV infection had severe disease or infection that led to fulminant hepatic failure. ${ }^{10} \mathrm{~A}$ review indicated that the case fatality rate among pregnant women with HEV infection is between $15 \%$ and $25 \%$, as compared with a range of 0.5 to $4 \%$ in the population overall. ${ }^{11}$ Among 220 consecutive pregnant women presenting with jaundice caused by acute viral hepatitis, fulminant hepatic failure and death were more common among women with HEV infection than among those without HEV infection (relative risk of fulminant hepatic failure, 2.7 ; relative risk of death, 6.0). ${ }^{12}$

\section{HSV INFECTION}

Pregnant women with primary HSV infection have an increased risk of dissemination and hepatitis (an otherwise rare complication in immunocompetent adults), particularly during the third trimester. To date, 27 cases of HSV hepatitis during pregnancy have been reported. ${ }^{13}$ After patients with immunosuppression, pregnant women are the largest group of adults with disseminated HSV infection; in one review, the mean gestational age at presentation was 31 weeks, and the case fatality rate was $39 \%$ for both mothers and neonates. ${ }^{14}$ Other reviews have confirmed a high burden of HSV hepatitis among pregnant women ${ }^{15,16}$; however, data on the incidence of primary HSV infection among pregnant women are limited. Recurrences of genital HSV infection increase in frequency during 
pregnancy, ${ }^{17}$ although the clinical characteristics of recurrent genital HSV infection are similar in pregnant women and nonpregnant women.

MALARIA

The severity of (and susceptibility to) Plasmodium falciparum malaria is determined by the level of immunity, which depends mainly on the intensity and stability of malaria transmission. In areas of low or unstable transmission, infected women become symptomatic, and, if untreated, the infection can progress rapidly to complications, with a high case fatality rate. In three districts in India, $23 \%$ or more of maternal deaths between 2004 and 2006 were attributable to malaria, which was the most common cause of maternal death during pregnancy. ${ }^{18}$ Pregnant women have a risk of severe malaria that is three times as high as that among nonpregnant women; a median maternal mortality of $39 \%$ has been reported in studies in the Asia-Pacific region. Maternal death also has been reported in association with $P$. vivax infection. ${ }^{18}$

In areas of high transmission, most women harboring parasites do not present with symptoms. It was thought that, in such areas, cases of severe or fatal malaria during pregnancy were rare. However, the numbers of maternal deaths from malaria in sub-Saharan Africa may have been underestimated, and malaria during pregnancy may be an important direct cause of maternal complications and death. ${ }^{19,20}$ Of pregnant women who are symptomatic, the majority are women having their first pregnancy; women who have been pregnant more than once and who live in areas where malaria is highly endemic are less likely to present with clinical signs or symptoms of malaria, even if they have high parasite loads. ${ }^{20,21}$ The predominant theory to explain this phenomenon is that $P$. falciparum parasites accumulate selectively in the placenta, and particular anti-genic variants interact with syncytiotrophoblastic chondroitin sulfate A. ${ }^{22}$ Women have a malaria episode caused by chondroitin sulfate A-binding parasites during their first pregnancy because they lack immunity to antigenic variants presented by these strains (even though they may be immune to other antigenic variants of parasites that bind endothelial receptors from previous infections) and are thus highly susceptible to the new infection.

\section{COCCIDIOIDOMYCOSIS}

Several reports and case series have suggested that pregnancy is a risk factor for the development of severe and disseminated coccidioidomycosis, particularly during the third trimester and the immediate postpartum period, with an estimated rate of 7.7 to 11 cases per 10,000 pregnancies. ${ }^{23-25}$ However, the rate of disease during pregnancy was much lower than expected in a large 1988 survey of records from three delivery centers in Tucson, Arizona, covering more than 47,000 deliveries. ${ }^{26}$ During the 1993 epidemic in Kern County, California, only 32 cases were identified among pregnant women, a lower number than expected; disseminated disease occurred in 3 of these cases, with no maternal deaths, ${ }^{27}$ which suggested that many pregnant women have asymptomatic or clinically mild disease. Taken together, these data suggest that the incidence of coccidioidomycosis is decreasing and that pregnant women may not be at increased risk for dissemination. 


\section{VARICELLA}

Early studies postulated that pregnancy, particularly in the third trimester, is a risk factor for severe varicella. These studies involved mostly case reports or small case series. ${ }^{28-30}$ In a 1990 review of 34 published cases of varicella pneumonia, mortality among pregnant women was $35 \%,{ }^{28}$ higher than that among nonpregnant adults, reported as $11.4 \%$ in another study. ${ }^{31}$ Paryani and Arvin reported a varicella pneumonia rate of 9\%, with one death among 43 pregnant women with varicella. ${ }^{30}$ A review of reports published from 1965 to 1989 on varicella pneumonia in adults showed that of 99 cases, 46 were in women; 28 of these women were pregnant ( $21 \mathrm{in}$ the third trimester). This suggested an increased rate of varicella pneumonia during pregnancy; however, mortality among pregnant women (10\%) was not higher than that among men and non-pregnant women. ${ }^{29}$ Other studies do not support the idea that illness due to varicella is more severe during pregnancy. In a New York City survey for the period from 1957 to 1964 , only 1 of 144 women with varicella died. ${ }^{32}$ In a study from Britain and Germany, in which 1373 women with varicella were followed during pregnancy, no maternal deaths were reported. ${ }^{33}$

\section{PREGNANCY AND SUSCEPTIBILITY TO INFECTION}

In contrast to the rather strong evidence for increased severity of certain infections among pregnant women, the evidence regarding initial susceptibility is weaker. The evidence for increased susceptibility during pregnancy is most credible for infections with organisms such as P. falciparum and Listeria monocytogenes, both of which have tropism for the placenta; evidence is more limited for human immunodeficiency virus type 1 infection (Table 1).

\section{MALARIA}

The harmful effects of malaria (mainly due to $P$. falciparum) during pregnancy - maternal anemia, low birth weight, and preterm birth — have long been recognized. ${ }^{19}$ In areas of stable endemic transmission (e.g., sub-Saharan Africa), up to $25 \%$ of pregnant women have acute infection, leading to placental malaria ${ }^{34}$; this frequency is higher than that among nonpregnant women. ${ }^{35,36}$ In several studies in Africa and Asia, the prevalence of malarial parasitemia was found to be higher among pregnant females than among nonpregnant females 15 to 45 years of age. ${ }^{18,37,38} P$. falciparum is the only species associated with placental sequestration, which is believed to be the cause of many of the manifestations of $P$. falciparum disease during pregnancy. Many studies have shown decreasing susceptibility to malaria with increasing parity, ${ }^{37-39}$ probably as a result of acquisition of immunity to parasites expressing pregnancy-specific variant surface antigens. ${ }^{19}$ This association is most pronounced in areas where malaria is highly endemic. ${ }^{20}$ Young maternal age may be an additional and independent risk factor for malaria during pregnancy. The third trimester of gestation has been associated with the highest risk of clinical malaria in some studies ${ }^{40}$ but not others. ${ }^{39}$ However, maternal parasitemia, placental parasite burden, and episodes of clinical malaria may be expressions of disease severity rather than of initial susceptibility in areas with a high prevalence of malaria. 
Limited data suggest that $P$. vivax infections also are more severe during pregnancy. ${ }^{18}$ These data, however, are difficult to interpret because most areas where $P$. vivax is the predominant cause of malaria have low or unstable transmission and therefore increased disease severity in all parity groups. ${ }^{41}$ Accumulation of $P$. vivax in the placenta has not been reported. ${ }^{42}$

\section{LISTERIOSIS}

Primarily a foodborne pathogen, listeria can contaminate a variety of raw foods, such as uncooked meats and vegetables, unpasteurized milk, and soft cheeses. Infection may be asymptomatic or may be manifested as an influenza-like illness; severe infection is rare during pregnancy, and no maternal deaths due to listeriosis have been reported among pregnant women who are hospitalized. ${ }^{43}$ L. monocytogenes infections most commonly occur during the third trimester and seem to be rare earlier in pregnancy. ${ }^{44}$ However, listeria has a predilection for the placenta and fetus, and, depending on the stage of pregnancy, listeriosis can lead to pregnancy loss, stillbirth, preterm birth, or serious neonatal disease. Active, population-based surveillance showed that $17 \%$ of 762 listeriosis cases reported in 10 U.S. sites between 2004 and 2009 were in pregnant women. ${ }^{45}$ Hispanic women seemed to be particularly at risk. ${ }^{45-47}$ It has been estimated that invasive listeriosis during pregnancy is 13 times to more than 100 times as frequent as in the general population. ${ }^{45,46,48}$ However, in one study, surveillance data indicated that more than $50 \%$ of listeriosis cases during pregnancy were associated with a neonatal case, ${ }^{45}$ which suggests that neonatal disease leads to recognition of listeria infections during pregnancy in a substantial proportion of cases and may therefore bias estimates of pregnancy-conferred risk.

\section{EVOLVING CONCEPTS OF IMMUNOLOGIC ALTERATIONS DURING PREGNANCY}

Immunologic alterations during pregnancy may help explain the altered severity of and susceptibility to infectious diseases during pregnancy. As pregnancy progresses, hormone levels change dramatically and are considerably higher than at any other time. ${ }^{49}$ The interplay between sex hormones and the immune system is complex and multifactorial, and it affects many organ systems (Fig. 1). In humans, estradiol can enhance several aspects of innate immunity and both cell-mediated and humoral adaptive immune responses. ${ }^{51,52}$ In general, low estradiol concentrations promote CD4+ type 1 helper T-cell (Th1) responses and cell-mediated immunity, and high estradiol concentrations augment CD4+ type 2 helper T-cell (Th2) responses and humoral immunity. ${ }^{52}$ Progesterone can suppress the maternal immune response and alter the balance between Th1 and Th2 responses. ${ }^{49,53,54}$ Increasing estrogen and progesterone concentrations with advancing pregnancy lead to a reversible thymic involution. The mechanisms of estrogen and progesterone modulation of individual components of the immune system have been extensively studied in vitro but not in humans. There is evidence that aspects of innate immunity (phagocytic activity, $\alpha$-defensin expression, and numbers of neutrophils, monocytes, and dendritic cells) are maintained or enhanced during pregnancy, particularly during the second and third trimesters. ${ }^{50,55}$ Conversely, the number of CD3+ T lymphocytes (both CD4+ and CD8+) decrease during pregnancy ${ }^{56,57}$ as do Th1 and Th2 responses to mitogenic or antigenic lymphocyte 
stimulation. ${ }^{55,58}$ However, there is limited information on the longitudinal trends of such alterations during pregnancy. Levels of several cytokines are altered: levels of interferon- $\gamma$, monocyte chemoattractant protein 1 , and eotaxin are decreased in most pregnant women, whereas tumor necrosis factor $a$, interleukin-10, and granulocyte colony-stimulating factor levels rise. ${ }^{50}$ In general, levels of inflammatory cytokines are reduced, whereas levels of cytokines that induce phagocytic-cell recruitment or activity increase; these alterations do not necessarily follow a clear Th1 or Th2 phenotype ${ }^{50}$ Regulatory T cells become more numerous. ${ }^{59}$

Several theories have been proposed to explain the immunologic alterations that occur during pregnancy. It was initially thought that pregnancy confers general immunosuppression to ensure tolerance of the semiallogeneic fetus. ${ }^{60}$ However, data indicating that fetus-specific cytotoxic $\mathrm{T}$-cell responses can be generated during pregnancy without loss of the fetus, ${ }^{61}$ as well as data from studies of pregnant mice showing normal memory T-cell development after lymphocytic choriomeningitis virus infection, ${ }^{62}$ contradict the idea of systemic immunosuppression during pregnancy. Adequate immunologic responses to vaccination in pregnant women have been demonstrated in several studies and for several pathogens. ${ }^{63-66}$

The fact that pregnant women do not seem, on the basis of epidemiologic evidence, to be more susceptible to infections in general also contradicts this theory. A more recent theory proposed a shift from Th1 to Th2 immunity during pregnancy. ${ }^{67} \mathrm{Th} 2$ cells stimulate B lymphocytes, increase antibody production, and suppress the cytotoxic T-lymphocyte response, decreasing the robustness of cell-mediated immunity. A shift to Th2 immunity is postulated to be responsible for altered responses to respiratory viral infections or autoantigens during pregnancy and could explain the increased severity of infections such as influenza or coccidioidomycosis, in which cell-mediated immunity is important. ${ }^{5,50,68}$

Elucidation of the immunologic alterations and adaptations that occur during pregnancy suggests that older concepts of pregnancy as a state of systemic immunosuppression are oversimplified. A more useful model may be the view of pregnancy as a modulated immunologic condition, not a state of immunosuppression. ${ }^{50}$ Decreases in adaptive immunity seen in later stages of pregnancy are consistent with the observed increase in the severity of certain infectious diseases during later pregnancy. Decreases in the numbers and function of CD4+, CD8+, and natural killer cells could affect antiviral, antifungal, or antiparasitic responses and delay clearance of the offending microorganism. However, the increases in innate immunity observed during pregnancy may help to prevent acquisition of infection and thus explain the absence of increased susceptibility to infections.

Furthermore, the placenta is an active immunologic site, capable of interacting with and responding to pathogens. The placental tropism of specific pathogens (e.g., listeria or $P$. falciparum) affects the susceptibility to and severity of certain infectious diseases during pregnancy, as well as pregnancy outcomes. ${ }^{54}$ Placental infection that elicits the production of inflammatory cytokines may activate the maternal immune system and lead to placental damage and miscarriage or preterm labor. ${ }^{69}$ Although a viral infection of the placenta that triggers a mild inflammatory response may not terminate the pregnancy, it can activate the 
maternal immune system or that of the fetus, potentially promoting an inflammatory response that may lead to long-term neurodevelopmental or other sequelae ${ }^{70}$ including diseases in adulthood, ${ }^{54}$ in the offspring.

\section{FUTURE DIRECTIONS}

The evidence of increased susceptibility of pregnant women to infection is rather weak; to adequately address this question, studies need to include nonpregnant age-matched controls, long prospective follow-up periods, and large samples. Even though pregnant women do not seem to be more susceptible than nonpregnant women to initial infection in general, immunologic alterations with advancing pregnancy may impair pathogen clearance, resulting in an increased severity of disease caused by some pathogens. Increased disease severity may also be due to other physiological changes of pregnancy (e.g., decreased lung capacity, urinary stasis, and changes in blood flow). There are many unanswered questions regarding the immunologic changes that occur as pregnancy progresses and the interplay of infection, pregnancy, and the fetus and placenta. The less detrimental effect of malaria in multiparous than in primiparous women could provide insights into disease pathogenesis during pregnancy that could be expanded to other infections, as well as to concepts of autoimmunity in general.

Given the hormonal shifts during pregnancy and the resultant effects on the immune system, efforts to reduce the pathogenesis of infectious and other diseases by modulating the hormonal environment locally or systemically warrant consideration. Approaches that boost pathogen-specific immunity or particular components of the immune system (e.g., alterations in certain cytokines and in regulatory T-cell subsets) may provide new prophylactic and therapeutic pathways. Interfering with the special interactions between some pathogens and the placenta may also offer a potential strategy for prophylaxis or therapy. Vaccination before and during pregnancy, which has proved safe and effective for a number of infectious agents, could one day be expanded to include vaccines against other relevant pathogens, such as HSV, HEV, and malaria parasites. The beneficial effects of maternal vaccination may not be limited to the mother but, by reducing fetal and placental inflammation, may also provide long-term benefits for the child. The education of pregnant women about prevention of infections and the early identification and appropriate treatment of infectious diseases during pregnancy remain important strategies for protecting maternal and infant health.

\section{References}

1. Finland M, Dublin TD. Pneumococcic pneumonia complicating pregnancy and the puerperium. JAMA. 1939; 250:1027-32.

2. Cervantes-Gonzalez M, Launay O. Pandemic influenza A (H1N1) in pregnant women: impact of early diagnosis and antiviral treatment. Expert Rev Anti Infect Ther. 2010; 8:981-4. [PubMed: 20818941]

3. Mosby LG, Rasmussen SA, Jamieson DJ. 2009 pandemic influenza A (H1N1) in pregnancy: a systematic review of the literature. Am J Obstet Gynecol. 2011; 205:10-8. [PubMed: 21345415]

4. Siston AM, Rasmussen SA, Honein AM, et al. Pandemic 2009 influenza A(H1N1) virus illness among pregnant women in the United States. JAMA. 2010; 303:1517-25. [PubMed: 20407061] 
5. Jamieson DJ, Theiler RN, Rasmussen SA. Emerging infections and pregnancy. Emerg Infect Dis. 2006; 12:1638-43. [PubMed: 17283611]

6. Neuzil KM, Reed GW, Mitchel EF, Simonsen L, Griffin MR. Impact of influenza on acute cardiopulmonary hospitalizations in pregnant women. Am J Epidemiol. 1998; 148:1094-102. [PubMed: 9850132]

7. Lindsay L, Jackson LA, Savitz DA, et al. Community influenza activity and risk of acute influenzalike illness episodes among healthy unvaccinated pregnant and postpartum women. Am J Epidemiol. 2006; 163:838-48. [PubMed: 16554352]

8. Rolland-Harris E, Vachon J, Kropp R, et al. Hospitalization of pregnant women with pandemic A(H1N1) 2009 influenza in Canada. Epidemiol Infect. 2012; 140:1316-27. [PubMed: 21920067]

9. Khuroo MS, Kamili S. Aetiology and prognostic factors in acute liver failure in India. J Viral Hepat. 2003; 10:224-31. [PubMed: 12753342]

10. Kumar A, Beniwal M, Kar P, Sharma JB, Murthy NS. Hepatitis E in pregnancy. Int J Gynaecol Obstet. 2004; 85:240-4. [PubMed: 15145258]

11. Aggarwal R, Krawczynski K. Hepatitis E: an overview and recent advances in clinical and laboratory research. J Gastroenterol Hepatol. 2000; 15:9-20. [PubMed: 10719741]

12. Patra S, Kumar A, Trivedi SS, Puri M, Sarin SK. Maternal and fetal outcomes in pregnant women with acute hepatitis E virus infection. Ann Intern Med. 2007; 147:28-33. [PubMed: 17606958]

13. Allen RH, Tuomala RE. Herpes simplex virus hepatitis causing acute liver dysfunction and thrombocytopenia in pregnancy. Obstet Gynecol. 2005; 106:1187-9. [PubMed: 16260566]

14. Kang AH, Graves CR. Herpes simplex hepatitis in pregnancy: a case report and review of the literature. Obstet Gynecol Surv. 1999; 54:463-8. [PubMed: 10394584]

15. Chase RA, Pottage JC Jr, Haber MH, Kistler G, Jensen D, Levin S. Herpes simplex viral hepatitis in adults: two case reports and review of literature. Rev Infect Dis. 1987; 9:329-33. [PubMed: 3589333]

16. Yaziji H, Hill T, Pitman TC, Cook CR, Schrodt GR. Gestational herpes simplex virus hepatitis. South Med J. 1997; 90:347-51. [PubMed: 9076313]

17. Brown ZA, Vontver LA, Benedetti J, et al. Genital herpes in pregnancy: risk factors associated with recurrences and asymptomatic viral shedding. Am J Obstet Gynecol. 1985; 153:24-30. [PubMed: 2994477]

18. Rijken MJ, McGready R, Boel ME, et al. Malaria in pregnancy in the Asia-Pacific region. Lancet Infect Dis. 2012; 12:75-88. [PubMed: 22192132]

19. Rogerson SJ. Malaria in pregnancy and the newborn. Adv Exp Med Biol. 2010; 659:139-52. [PubMed: 20204762]

20. Menendez C. Malaria during pregnancy. Curr Mol Med. 2006; 6:269-73. [PubMed: 16515517]

21. van Eijk AM, Ayisi JG, ter Kuile FO, et al. Risk factors for malaria in pregnancy in an urban and peri-urban population in western Kenya. Trans R Soc Trop Med Hyg. 2002; 96:586-92. [PubMed: 12625128]

22. Fried M, Duffy PE. Adherence of Plasmodium falciparum to chondroitin sulfate A in the human placenta. Science. 1996; 272:1502-4. [PubMed: 8633247]

23. Smale LE, Waechter KG. Dissemination of coccidioidomycosis in pregnancy. Am J Obstet Gynecol. 1970; 107:356-61. [PubMed: 5445005]

24. Vaughan JE, Ramirez H. Coccidioidomycosis as a complication of pregnancy. Calif Med. 1951; 74:121-5. [PubMed: 14801727]

25. Bercovitch RS, Catanzaro A, Schwartz BS, Pappagianis D, Watts DH, Ampel NM. Coccidioidomycosis during pregnancy: a review and recommendations for management. Clin Infect Dis. 2011; 53:363-8. [PubMed: 21810749]

26. Wack EE, Ampel NM, Galgiani JN, Bronnimann DA. Coccidioidomycosis during pregnancy: an analysis of ten cases among 47,120 pregnancies. Chest. 1988; 94:376-9. [PubMed: 3396418]

27. Caldwell JW, Arsura EL, Kilgore WB, Garcia AL, Reddy V, Johnson RH. Coccidioidomycosis in pregnancy during an epidemic in California. Obstet Gynecol. 2000; 95:236-9. [PubMed: 10674586] 
28. Haake DA, Zakowski PC, Haake DL, Bryson YJ. Early treatment with acyclovir for varicella pneumonia in otherwise healthy adults: retrospective controlled study and review. Rev Infect Dis. 1990; 12:788-98. [PubMed: 2237118]

29. Esmonde TF, Herdman G, Anderson G. Chickenpox pneumonia: an association with pregnancy. Thorax. 1989; 44:812-5. [PubMed: 2688179]

30. Paryani SG, Arvin AM. Intrauterine infection with varicella-zoster virus after maternal varicella. N Engl J Med. 1986; 314:1542-6. [PubMed: 3012334]

31. Triebwasser JH, Harris RE, Bryant RE, Rhoades ER. Varicella pneumonia in adults: report of seven cases and a review of literature. Medicine (Baltimore). 1967; 46:409-23. [PubMed: 4864340]

32. Siegel M. Congenital malformations following chickenpox, measles, mumps, and hepatitis: results of a cohort study. JAMA. 1973; 226:1521-4. [PubMed: 4800931]

33. Enders G. Varicella-zoster virus infection in pregnancy. Prog Med Virol. 1984; 29:166-96. [PubMed: 6322232]

34. Dauby N, Goetghebuer T, Kollmann TR, Levy J, Marchant A. Uninfected but not unaffected: chronic maternal infections during pregnancy, fetal immunity, and susceptibility to postnatal infections. Lancet Infect Dis. 2012; 12:330-40. [PubMed: 22364680]

35. Gilles HM, Lawson JB, Sibellas M, Voller A, Allan N. Malaria and pregnancy. Trans R Soc Trop Med Hyg. 1969; 63:1. [PubMed: 5789098]

36. Brabin BJ. An analysis of malaria in pregnancy in Africa. Bull World Health Organ. 1983; 61:1005-16. [PubMed: 6370484]

37. McGregor IA. Epidemiology, malaria and pregnancy. Am J Trop Med Hyg. 1984; 33:517-25. [PubMed: 6383091]

38. Taylor SM, van Eijk AM, Hand CC, et al. Quantification of the burden and consequences of pregnancy-associated malaria in the Democratic Republic of the Congo. J Infect Dis. 2011; 204:1762-71. [PubMed: 21990422]

39. Bray RS, Anderson MJ. Falciparum malaria and pregnancy. Trans R Soc Trop Med Hyg. 1979; 73:427-31. [PubMed: 400205]

40. Adam I, Khamis AH, Elbashir MI. Prevalence and risk factors for Plasmodium falciparum malaria in pregnant women of eastern Sudan. Malar J. 2005; 4:18. [PubMed: 15829008]

41. Brutus L, Santalla J, Schneider D, Avila JC, Deloron P. Plasmodium vivax malaria during pregnancy, Bolivia. Emerg Infect Dis. 2013; 19:1605-11. [PubMed: 24050302]

42. Chotivanich K, Udomsangpetch R, Suwanarusk R, et al. Plasmodium vivax adherence to placental glycosaminoglycans. PLoS One. 2012; 7(4):e34509. [PubMed: 22529919]

43. Smith JL. Foodborne infections during pregnancy. J Food Prot. 1999; 62:818-29. [PubMed: 10419281]

44. Gellin BG, Broome CV, Bibb WF, Weaver RE, Gaventa S, Mascola L. The epidemiology of listeriosis in the United States — 1986. Am J Epidemiol. 1991; 133:392-401. [PubMed: 1899779]

45. Silk BJ, Date KA, Jackson KA, et al. Invasive listeriosis in the Foodborne Diseases Active Surveillance Network (FoodNet), 2004-2009: further targeted prevention needed for higher-risk groups. Clin Infect Dis. 2012; 54(Suppl 5):S396-S404. [PubMed: 22572660]

46. Mylonakis E, Paliou M, Hohmann EL, Calderwood SB, Wing EJ. Listeriosis during pregnancy: a case series and review of 222 cases. Medicine (Baltimore). 2002; 81:260-9. [PubMed: 12169881]

47. Pouillot R, Hoelzer K, Jackson KA, Henao OL, Silk BJ. Relative risk of listeriosis in Foodborne Diseases Active Surveillance Network (FoodNet) sites according to age, pregnancy, and ethnicity. Clin Infect Dis. 2012; 54(Suppl 5):S405-S410. [PubMed: 22572661]

48. Goulet V, Hebert M, Hedberg C, et al. Incidence of listeriosis and related mortality among groups at risk of acquiring listeriosis. Clin Infect Dis. 2012; 54:652-60. [PubMed: 22157172]

49. Robinson DP, Klein SL. Pregnancy and pregnancy-associated hormones alter immune responses and disease pathogenesis. Horm Behav. 2012; 62:263-71. [PubMed: 22406114]

50. Pazos M, Sperling RS, Moran TM, Kraus TA. The influence of pregnancy on systemic immunity. Immunol Res. 2012; 54:254-61. [PubMed: 22447351] 
51. Cvoro A, Tatomer D, Tee MK, Zogovic T, Harris HA, Leitman DC. Selective estrogen receptorbeta agonists repress transcription of proinflammatory genes. J Immunol. 2008; 180:630-6. [PubMed: 18097065]

52. Straub RH. The complex role of estrogens in inflammation. Endocr Rev. 2007; 28:521-74. [PubMed: 17640948]

53. Szekeres-Bartho J, Wegmann TG. A progesterone-dependent immunomodulatory protein alters the Th1/Th2 balance. J Reprod Immunol. 1996; 31:81-95. [PubMed: 8887124]

54. Mor G, Cardenas I. The immune system in pregnancy: a unique complexity. Am J Reprod Immunol. 2010; 63:425-33. [PubMed: 20367629]

55. Kraus TA, Engel SM, Sperling RS, et al. Characterizing the pregnancy immune phenotype: results of the Viral Immunity and Pregnancy (VIP) study. J Clin Immunol. 2012; 32:300-11. [PubMed: 22198680]

56. Zoller AL, Schnell FJ, Kersh GJ. Murine pregnancy leads to reduced proliferation of maternal thymocytes and decreased thymic emigration. Immunology. 2007; 121:207-15. [PubMed: 17250584]

57. Clarke AG, Kendall MD. The thymus in pregnancy: the interplay of neural, endocrine and immune influences. Immunol Today. 1994; 15:545-51. [PubMed: 7802926]

58. Forbes RL, Gibson PG, Murphy VE, Wark PAB. Impaired type I and III interferon response to rhinovirus infection during pregnancy and asthma. Thorax. 2012; 67:209-14. [PubMed: 21917654]

59. Somerset DA, Zheng Y, Kilby MD, Sansom DM, Drayson MT. Normal human pregnancy is associated with an elevation in the immune suppressive CD25+CD4+ regulatory T-cell subset. Immunology. 2004; 112:38-43. [PubMed: 15096182]

60. Medawar P. Some immunological and endocrinological problems raised by the evolution of viviparity in vertebrates. Symp Soc Exp Biol. 1953; 7:320-38.

61. Lissauer D, Piper K, Goodyear O, Kilby MD, Moss PA. Fetal-specific CD8+ cytotoxic T cell responses develop during normal human pregnancy and exhibit broad functional capacity. $\mathrm{J}$ Immunol. 2012; 189:1072-80. [PubMed: 22685312]

62. Constantin CM, Masopust D, Gourley T, et al. Normal establishment of virus-specific memory CD8 T cell pool following primary infection during pregnancy. J Immunol. 2007; 179:4383-9. [PubMed: 17878333]

63. Sperling RS, Engel SM, Wallenstein S, et al. Immunogenicity of trivalent inactivated influenza vaccination received during pregnancy or postpartum. Obstet Gynecol. 2012; 119:631-9. [PubMed: 22353963]

64. Ohfuji S, Fukushima W, Deguchi M, et al. Immunogenicity of a monovalent 2009 influenza A (H1N1) vaccine among pregnant women: lowered antibody response by prior seasonal vaccination. J Infect Dis. 2011; 203:1301-8. [PubMed: 21459817]

65. Healy CM. Vaccines in pregnant women and research initiatives. Clin Obstet Gynecol. 2012; 55:474-86. [PubMed: 22510631]

66. Munoz, FM.; Bond, NH.; Maccato, M., et al. Safety and immunogenicity of Tdap vaccine in healthy pregnant women, safety in their neonates, and effect of maternal immunization on infant immune responses to DTaP vaccine. Presented at the 2nd International Maternal Neonatal Immunization Symposium; Antalya, Turkey. March 1-3, 2013; abstract

67. Wegmann TG, Lin H, Guilbert L, Mosmann TR. Bidirectional cytokine interactions in the maternal-fetal relationship: is successful pregnancy a TH2 phenomenon? Immunol Today. 1993; 14:353-6. [PubMed: 8363725]

68. Ostensen M, Villiger PM. Immunology of pregnancy-pregnancy as a remission inducing agent in rheumatoid arthritis. Transpl Immunol. 2002; 9:155-60. [PubMed: 12180824]

69. Koga K, Cardenas I, Aldo P, et al. Activation of TLR3 in the trophoblast is associated with preterm delivery. Am J Reprod Immunol. 2009; 61:196-212. [PubMed: 19239422]

70. Cardenas I, Aldo P, Koga K, Means R, Lang SH, Mor G. Subclinical viral infection in pregnancy lead to inflammatory process at the placenta with non-lethal fetal damage. Am J Reprod Immunol. $2009 ; 61: 397$. 


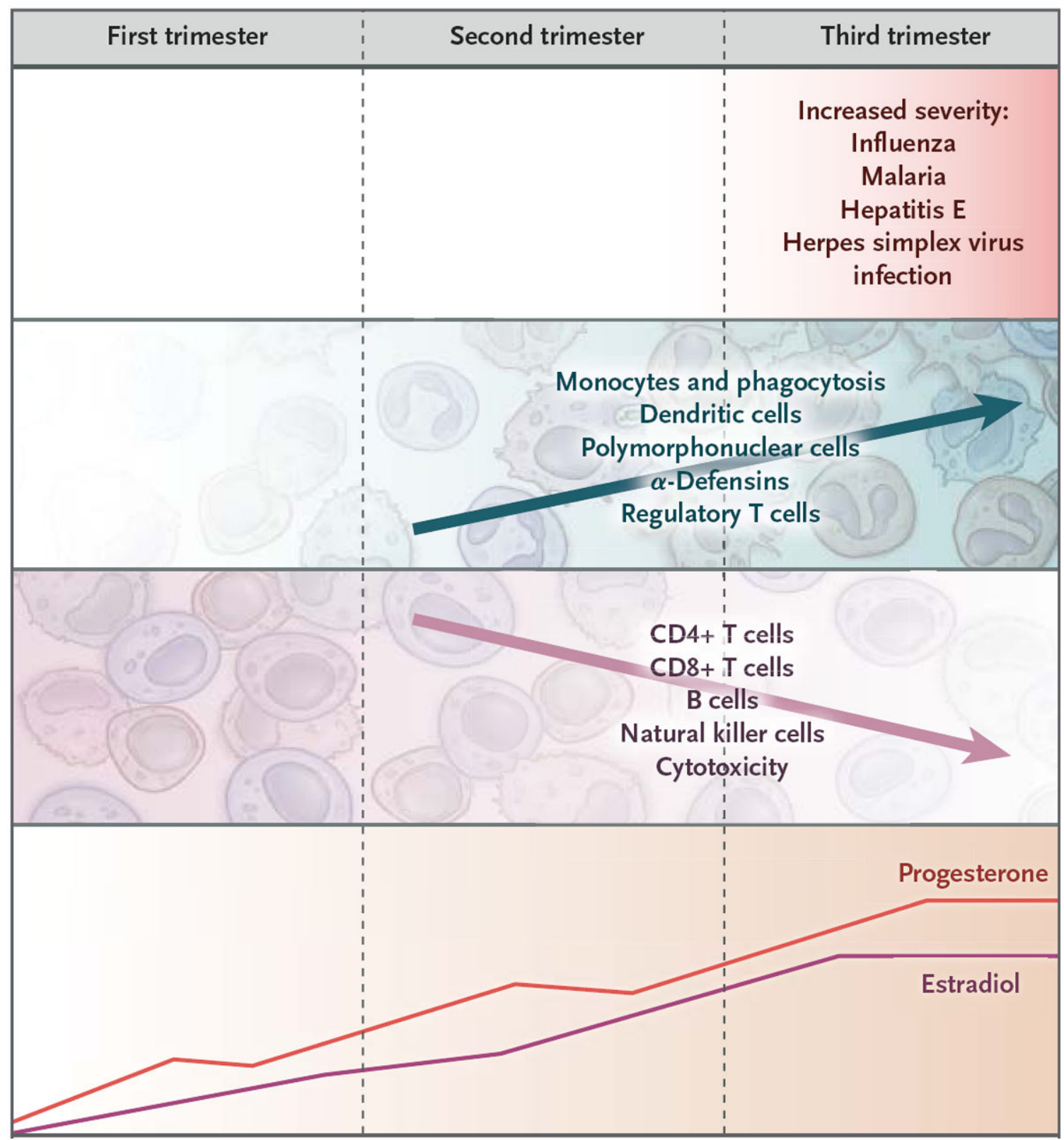

Figure 1. Changes in Hormone Levels and Immune-System Characteristics during Pregnancy As pregnancy advances, T-cell activity, natural killer cell activity, and possibly B-cell activity are reduced, whereas $\alpha$-defensin levels and monocyte, dendritic-cell, and polymorphonuclear-cell activity are increased. ${ }^{49,50}$ The severity of some infections (particularly influenza, malaria, hepatitis E, and herpes simplex virus hepatitis and dissemination) increases with advancing pregnancy. 


\section{Table 1}

Infections Associated with Increased Susceptibility or Severity among Pregnant Women, and Relevant Clinical Guidance, According to the Strength of the Evidence for an Association.

\begin{tabular}{|c|c|c|c|c|}
\hline Infection & Increased Susceptibility & Increased Severity & Prevention Strategies & Management Strategies ${ }^{*}$ \\
\hline \multicolumn{5}{|l|}{ Stronger evidence } \\
\hline Influenza & No & Yes & $\begin{array}{l}\text { Influenza vaccination; } \\
\text { antiviral prophylactic } \\
\text { medication for selected } \\
\text { patients }\end{array}$ & $\begin{array}{l}\text { Early identification; early } \\
\text { antiviral therapy; supportive } \\
\text { care }\end{array}$ \\
\hline $\begin{array}{l}\text { Hepatitis E virus } \\
\text { infection }\end{array}$ & No & Yes & Sanitation programs & $\begin{array}{l}\text { High index of clinical } \\
\text { suspicion; supportive care }\end{array}$ \\
\hline $\begin{array}{l}\text { Herpes simplex virus } \\
\text { infection (dissemination } \\
\text { with primary infection) }\end{array}$ & No & Yes & $\begin{array}{l}\text { Protection from sexually } \\
\text { transmitted infections } \\
\text { during pregnancy }\end{array}$ & $\begin{array}{l}\text { High index of clinical } \\
\text { suspicion; antiviral therapy; } \\
\text { supportive care; care of the } \\
\text { newborn }\end{array}$ \\
\hline $\begin{array}{l}\text { Malaria (mainly due to } \\
\text { Plasmodium falciparum) }\end{array}$ & Yes & Yes & $\begin{array}{l}\text { Intermittent preventive } \\
\text { therapy; insecticide-treated } \\
\text { bed nets (for areas where } \\
\text { malaria is endemic); } \\
\text { appropriate prophylaxis } \\
\text { (for travelers) }\end{array}$ & $\begin{array}{l}\text { Early identification; appropriate } \\
\text { antimalarial therapy; supportive } \\
\text { care }\end{array}$ \\
\hline Listeriosis & Yes & No & Dietary guidance & $\begin{array}{l}\text { Early identification; appropriate } \\
\text { anti-microbial therapy; care of } \\
\text { the newborn }\end{array}$ \\
\hline \multicolumn{5}{|l|}{ More limited evidence } \\
\hline Measles & No & Yes & Vaccination & $\begin{array}{l}\text { High index of clinical } \\
\text { suspicion; supportive care }\end{array}$ \\
\hline Smallpox & No & Yes & Vaccination & $\begin{array}{l}\text { Very high index of clinical } \\
\text { suspicion; supportive care }\end{array}$ \\
\hline $\begin{array}{l}\text { Human } \\
\text { immunodeficiency virus } \\
\text { type } 1 \text { infection }\end{array}$ & Yes & No & $\begin{array}{l}\text { Consistent and correct } \\
\text { condom use; protection } \\
\text { from sexually transmitted } \\
\text { diseases during pregnancy }\end{array}$ & $\begin{array}{l}\text { Early identification; } \\
\text { antiretroviral therapy }\end{array}$ \\
\hline Varicella & No & Yes & Vaccination & $\begin{array}{l}\text { Appropriate antiviral therapy; } \\
\text { supportive care }\end{array}$ \\
\hline Coccidioidomycosis & No & Yes & $\begin{array}{l}\text { No proven methods of } \\
\text { prevention }\end{array}$ & $\begin{array}{l}\text { Early identification; appropriate } \\
\text { antifungal therapy }\end{array}$ \\
\hline
\end{tabular}

Infections for which there should be a higher or very high index of clinical suspicion are those that must be considered by the clinician despite being rare diagnoses in some areas. 